\title{
Exploring Social Outcomes of Interactions between University Students and Waala Communities in the Wa Municipality, Ghana
}

\author{
Emmanuel K. Derbile \\ Department of Planning and Management \\ University for Development Studies, Wa Campus, UWR \\ derbile_uds@hotmail.com \\ and \\ Francis Dakyaga, Gordon Dakuu and Lazarus Jambadu \\ Department of Planning and Management \\ University for Development Studies, Wa Campus, UWR \\ DOI//http://dx.doi.org/10.4314/gjds.v13i1.4
}

\begin{abstract}
In the context of social integration theory, this paper explores the social outcomes of interactions between university students and indigenous Waala communities in the Wa Municipality, northwestern Ghana. Drawing on results from focus group discussions and in-depth interviews, weposit that social integration outcomes have been both positive and negative, the latter being predominant. In the positive domain, university students from varied ethnic backgrounds are socially accepted to live in shared rental accommodation by indigenous Waala families and by extension allowing for modest cross-cultural learning's and exchanges. University students, especially female students serve as role models in education to Waala youth, particularly, young girls - inspiring them to attain higher education. In the negative domain, the outcomes include conflicts between students and Waala families over varied ways of life, conflicts over rents and ejection of students from rental apartments, exploitation of studentsthrough application of higher rents and market prices ofconsumer goods and finally, increasing incidences of love relationships between students and indigenes leading to social tensions and undesirable outcomes. We therefore, arguethat integration of students into the Waala community has been partial and underpinned by differentiated ways of lives, culture and conflicts that has undermined the process of acculturation. Thus, the paper advocates an integrated approach to Municipal Development Planning (MDP) through multi - stakeholder engagement for the promotion of education, platforms for dialogue, and strengthening institutions for dealing with emerging issues and conflicts arising from the processes of social integration.
\end{abstract}

Keywords: Social Interactions, Social Integration, Students, Indigenes, Ghana 


\section{Introduction}

This paper analyses the outcomes of the social integration of students of the University for Development Studies (UDS) at Wa into Waala communities and families in the Wa Municipality. Over the past decade, the Wa-Municipality has experienced an unprecedented rate of urbanization, partly attributed to the influx of a temporary university student population of the University for Development Studies (UDS). Most of these students are accommodated in shared private residential accommodation commonly referred to as compound houses in the city and its suburbs. This has brought students close to the indigenous people, the Waala, leading to close social and economic interactions between the two groups. This paper therefore draws on social integration theory for analysing the outcomes of the interactions between university students on the one hand and indigenous Waala communities and families on the other hand.

The paper is organized in five sections, the first being this introductory section. The next section is devoted to an overview of urbanization and the study methodology. In section three, the results and outcomes of social integration are presented. This is followed by a discussion and conclusion in sections four and five respectively.

\section{The Study Area and Methodology}

Historically, Wa has served as the headquarters of the Waala state and a rest stop for the Trans-Saharan traders prior to colonization. Even after colonization, Wa served as a service centre and it still plays this role till date. Currently, it is the regional capital of the Upper West Region, the last region of the ten regions of Ghana to be established on 14th January, 1983. It plays political and administrative functions and provides a wide range of administrative, commercial and financial services to the rest of the region.

The Wa Municipality has experienced a phenomenal rate of urbanization over the past two decades, most of the demographic change occurring within the last decade. The municipality is the largest urban settlement in the region with a population of 71,051 in 2010 growing from 13,740 in 1970, 36067 in 1984, 66644 in 2000 (GSS, 1984; GSS, 2000; GSS, 2010). The municipality experienced an inter-censual growth rate of 84.7 per cent between 1984 and 2000. Much of this growth is attributed to high fertility rate and immigration. For instance, total fertility rate for the region is 5.0 compared to a national figure of 3.1 for urban areas in the country and 4.0 for the whole country (GSS, 2008). Consequentially, population growth rate is estimated at 2.7 percent for the region and 1.7 percent for the country (GSS, 2000).

Migration is one of the main causes of demographic change in the Wa Municipality and some of this is caused by the immigration of tertiary student population, especially students of UDS following the location of a campus of the university (UDS Wa Campus). Total student enrolment of the campus increased from 6000 in the $2008 / 9$ academic year to about 12000 in the 2012/13 academic year (Figure 1). 
Figure 1. Student enrolment from 2008 to 2013 at the Wa Campus

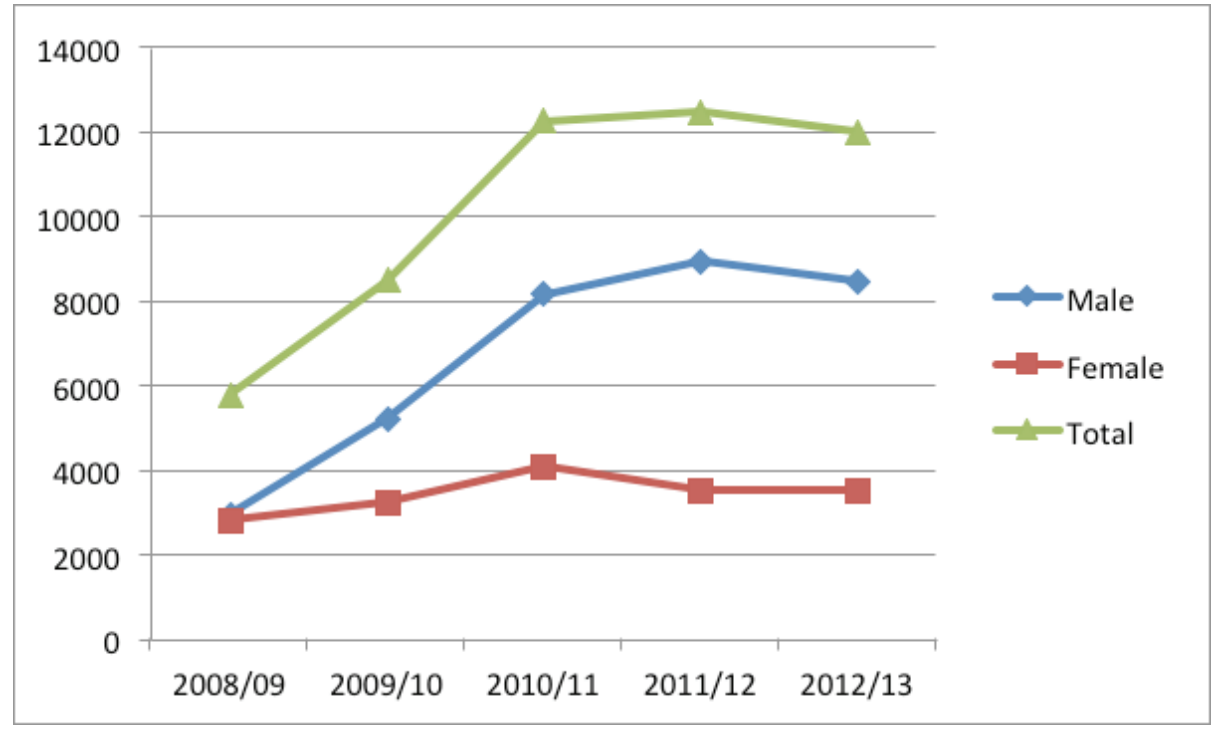

It is clear from the analysis (Figure 1) that student enrolments have consistently increased over the years and this coupled with other immigration streams and fertility rates has spurred demand for housing accommodation in the municipality. The housing stock in the municipality has increased over the years. For example it increased from 8,788 in 1984 to 20,551 as of the 2000 population and housing census (GSS, 1984; GSS, 2000). Nonetheless, demand far exceeds supply in the housing market and this has given room to abuses of tenants and or will be tenants by landlords/ladies in the municipality much the same way it occurs across other cities across the country. Accordingly, landlords in cities of Ghana blatantly breach the rent law and abuse tenants in pursuit of their self-interest (Songsore, 2003). Although the Rent Control Department (RCD) was established under the Rent Act of 1963 for mediating between landlords and tenants interest, it has not fared well in performing its function due to capacity problems.

This paper draws mainly on a qualitative study that employed eight focus group discussions (FGDs) among four categories of respondents/discussants. The Wa Municipality has over 15 communities or neighbourhoods that together constitute the Wa Municipality. The FGDs were conducted in four purposively sampled communities (neighbourhoods). The sampling was informed by the level of concentration of student population in the neighbourhood, with preference for neighbourhoods that had the highest concentration of students and indigenous Waala families..These included Bamahu and Dobilecommunities with high student populations. The rest included two market squares, one in the Central Business District (CBD) and the other in Kanbali - both of whom provide residential accommodation and commercial services for indigenes and students. 
The focus group discussions (FGDs) were conducted among different categories of discussants for the purpose of triangulating the sources of data. The distribution of FGDs conducted were as follows: two among female university students, two among male university students, two among Waala men and two among Waala women, most of whom were petty traders. The data was analysed by means of detailed description, paraphrasing and use of boxes and tables.

\section{Theory of Social Integration}

In general the theory of social integration suggest mechanisms by which a group of people, very often a minorty group are brought into mainstream societal life and or are accepted by the host group of people, the majority. According to the United Nations Research Institute for Social Development [UNRISD] (1994), social integration may be understood and or applied in three varied ways. First, it can be applied in the sense of an inclusionary orientation in which the goal of integration is to improve life chances through equal opportunities and rights for all human beings, particularly the minority group. Secondly, it may be applied in the sense of imposing some cultural values on a minority group for the sake of engendering uniformity in society. Lastly, it may also be applied as a way of simply describing the emerging patterns of human relations arising from the secularization of society.

According to Krauße, (1991) and Münch (1998), social integration depicts a situation in which all parts of a society are closely in conjunction with each other and united. Social Integration depicts inclusion and the extent to which all shades of people in a society cooperate, mutually interact and associate themselves with other people regardless of any forms of differentiation and the associated effects of interaction. According to Beresnevieriute (2003), social integration determines connections of related diverse elements into the social whole, system, community, or other unit. Koramaz (2013) views social integration, as the harmonious and coherent processing of the structures of a social system. Adding that, integration should engender equal rights and opportunities, shared values, trust, a sense of belonging to society and social networking. According to Koramaz's view, when people move from one spatial location to the other, their ability to function adequately depends on the extent of their integration, that is, perceived belongingness to the society, social networks, shared trust, equal rights and opportunities and the unique attributes they share with their neighbors (Kormaz, 2013). Although social integration is inevitable in the light of globalization, crisis situations and increasing migration, social integration processes can either lead to inclusion or full integration or exclusion, requiring legislation to regulate the integration process for preventing the potential loss of inclusion to exclusion (Munch, 1998; Krauße, 1991; Guralnick, 1999; Koramaz, 2013).

The origin of social integration theory is attributed to Emile Durkheim, a French sociologist, in his works in the late 19th century that helped establish sociology as a distinct field of study from other social science disciplines like psychology. He considered social integration as the means through which people interact, connect and confirm each other 
within a community. The theory proposes that "people experience mental, emotional and physical benefits when they believe they are contributing and accepted part of a collective. Without that sense of connection, they can experience depression, isolation and physical illness that could limit them from experiencing productive, happy lives." (Hardy. n.d:1; Marijkkeanker, 2011). Durkheim explained how social order varied and was maintained in pre-modern and modern societies. He explained that the transition from traditional society to modern society as driven by industrialization and the division of labour was associated with a transition from "mechanical" solidarity to "organic" solidarity as part of his theory of the development of societies in The Division of Labour in Society (1893). In mechanical societies, usually traditional, small scale and simple societies, social cohesion and integration come from the homogeneity of individuals and bounded by a common culture, including upholding similar values, common work and life style and kinship ties and familial networks. This is distinct from organic solidarity. The interdependence that arises from specialization of work and complementarities between people in a modern and industrial society is what gives rise to organic solidarity. Thus, it is clear that solidarity, be it mechanical or organic, is the key to societal cohesion. According to Blau (1960), social integration therefore, prevails if bonds of attraction unite its members and that persons interested in becoming integrated are often under pressure to impress the host group that they would make attractive associates.

For this paper, social integration is applied more in the sense of it being inclusionary of minority groups and as a way of describing the emerging patterns of human relations arising from the secularization of society.

\section{Results and Outcomes}

The results of interaction of students and indigenous Waala communities and families have yielded both positive and negative integration outcomes. Starting from the positive outcomes, the interactions between the two have resulted in a modest degree of social acceptability, cross cultural learning and the promotion of formal education among the Waala youth.

First, the interaction of students and indigenous Waala families has resulted in modest degree of social acceptability and cross cultural learning. Social acceptability of students to live within indigenous Waala communities and among families - but this is also driven by economic interest, rent payments indigenous house owners derive from the students. From the records, a large array of students find physical and social space among indigenous Waala communities and families, most of whom not having access to university hostel accommodation. For instance, in the 2012/13 academic year, the total student population was 12021 out of which only 6\% (700) were accommodated in university hostels. Thus, about $94 \%$ of the student population have to find private accommodation in compound houses where they live with Waala families. 
Secondly, the social interactions between university students who come from a wide diversity of cultural backgrounds across the country and Waala families have also led to modest cross-cultural learning and exchange of values and experiences through living together. According to a female rice seller, "Some of the students do pray with us, greet us very well and have regard for elders. This is how we want our children to be, there is a male student in my house; he is very respectful, he helps even when you haven't asked him. I wish all UDS students were like this". According to male FGD discussants Dobile and Bamahu:

Some of the students are very friendly and good to us in the house. As such, they easily learn Waale, the local language but we really don't learn their languages like that because this is our home (FGD discussants, Dobile, June 15, 2013).

Students learn our language (waale) a lot and sometimes we also do learn theirs a bit. They also eat our traditional food, popularly known as Tuozaafi (TZ). Some students like it very much (FGD discussants, Bamahu, July 20, 2013).

Female discussants, mainly petty traders, corroborate the assertions made by their male counterparts that cross-cultural learning and exchange of social values occur between students and natives. Accordingly:

Most students, especially female students from southern Ghana learn how to prepare indigenous Waala meals such as T.Z and vegetable soup, bean cakes (Koose) and tubani. They assert that most female students learn how to prepare T.Z in particular before they complete. Conversely, we also learn how to prepare fufu with cassava and plantain from them. This is different from what we know, that is, preparing fufu with yam only. Even as women, we learn how some stews and soups are prepared to go with main meals. It is really lively. Many more male and female students learn how to eat T.Z even if they can't cook it(Female student discussants, Bamahu, July 20, 2013).

The third positive outcome is that university students serve as role models of education to the Waala youth. In particular, female students have had a positive impact on indigenous Waala youth, especially Waala girls - inspiring them to attain higher education. It should be observed that illiteracy rates among indigenous Waala communities have been high and still is. Parents, especially mothers have also been influenced positively about the need for education. Some extracts from male discussants in Dobile shed light on this:

University students have served as role models to some of our female students and now they actually aspire to attain higher education like them.

As for education, we all know that prior to UDS, many people, even the elderly did not take education seriously but now children have actually been influenced by the university students and the very presence of the university here (Male FGD discussants[Waala men], Dobile, June 15, 203.). 
Female FGD discussants in Bamahu and Dobile corroborate the assertions of their male counterparts that university students have influenced their children positively in terms of inspiration for attaining high education, especially the female students influencing Waala girls. They cite a number of changes and examples to support their assertion (Box 1).

Box 1: University students as role models of education to Waala youth

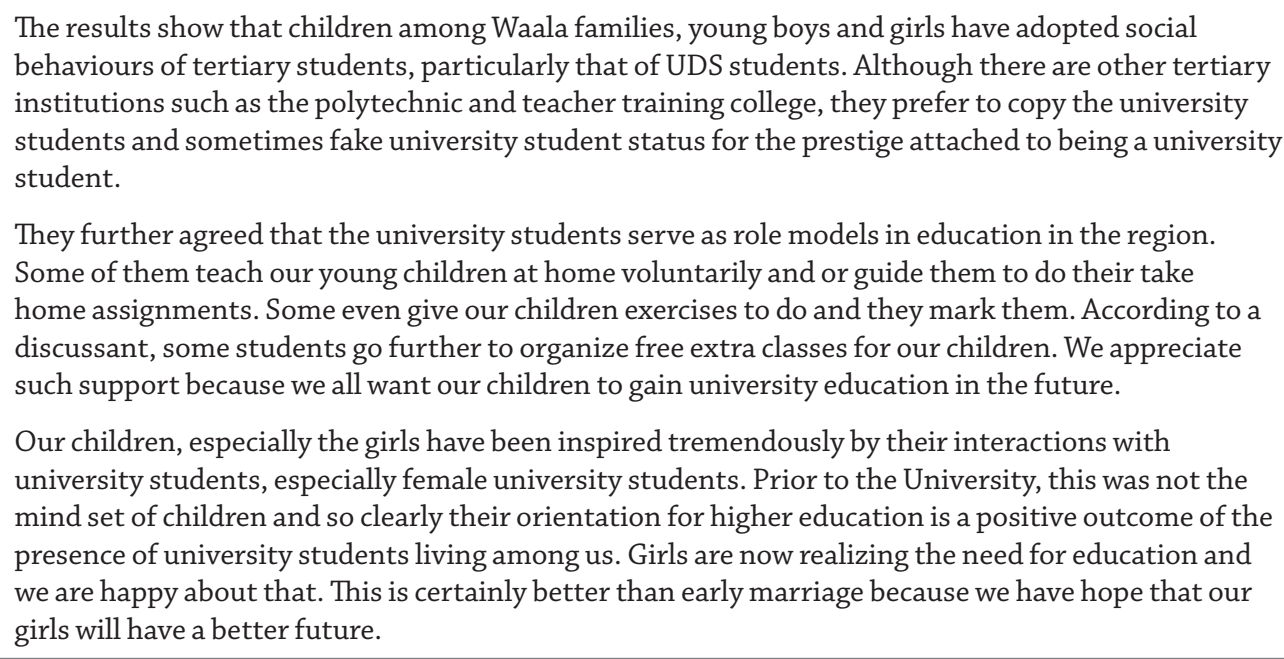

The interaction of university students and their host communities has led to a number of negative outcomes, the first being conflict between students and indigenous Waala families over different ways of social life. Very often, abhorrence, especially of indigenous Waala families of the way of life of students leads to social tension and in extreme cases verbal and physical assaults or violence. Extracts from the contribution of male FGD discussants in Bamahu reveal the dislike of the dressing styles of female university students:

- They are not our children but their way of dressing is very bad. In this community, we are Muslims and this worries us because our children are learning how to dress like these female university students.

- There is nothing good about the dressing of female university students.

- The dressing of these students is very bad and they have changed our children's way of dressing. Our children are now also wearing miniskirts, short dresses and tops that expose part of their bodies, even including their breasts.

- Students, especially female students wear hanging tops, tight trousers, short skirts and dresses that expose their breasts.

Instances of conflicts between students and indigenous Waala families are common and arise for varied reasons related to unacceptability of the behaviour of students by host families or co-tenants. According to male FGD discussants in Bamahu: 
Very often we quarrel with students in the house due to their bad behaviour and disrespect for elders. They don't respect us because we are illiterates. They don't pay light bills; they refuse to scrub and clean bathrooms and general surroundings, especially among the girls. A student will rent a room from you as an individual and by the next day you see a pair of or even more than two students. Very often they try to cheat on us this way. Even sometimes, male and female students living together (cohabitation) against our will. What some do is that, they re-rent to colleagues at even higher rates and then they live together as roommates without the consent of us landlords. They also punch holes on our walls even against our advice (Male FGD discussants [Waala men], Bamahu, July 20, 2013).

Male FGD discussants from Dobile corroborate what those in Bamahu said:

As for their dressing, we had better not talk about it. The female students wear short skirts they call miniskirts. The male students dress like crazy people with their trousers hanging and their panties and bums showing. Even female students also expose their panties and bums in the same wear as a fashionable dressing style called 'I am aware'. These students display very bad, funny and unacceptable dressing. We see them every day inour houses because they live with us. In our own families, we can see the changes in the dressings of our children, particularly the girls (Male FGD discussants [Waala men], Bamahu, July 20, 2013).

Female FGD discussants (women/traders) mentioned multiple and several negative outcomes arising from students and indigenous community interactions (Box 2). 


\section{Box 2: Unacceptable student behaviour as described by Waala women and traders}

Women expressed their disappointment and dislike of the way university students dress, both male and particularly females being women themselves. They particularly make reference to days that students organize 'road show floats' as part of celebration of SRC activities. They wear red, dress in weird ways and promote some extend of nudity on the streets of Wa and across the town.

Their worry is that their youth, especially the girls are copying these bad ways of dressing-blindly. Accordingly, the days in which Waala girls dressed very well, such as wearing long dresses and scarfs (Mariyafi) to cover their bodies sufficiently, and consistent with Islamic traditions are long gone. Even in the past, non-Muslims also dressed well and elderly women felt good and proud to be called by them their mother in laws. Now, most Waala girls think it is a fashion to expose their breasts and buttocks on the street, commonly referred to as "Gentira" dressings. They even do it with impunity.

Even our own daughters in UDS want to wear short skirts and expose their buttocks and breast and they think it is normal. Some Waala girls now go out and come home very late. According to one respondent, some of the guys are womanizers and are always changing women here and there and when we complain they think we are interfering in their privacy.

According to one vegetable seller, I had two UDS students in my house, they were very dirty. They don't do anything in the house even their rooms. But when you see them outside you think they are angels. And our children copy them blindly.

Another social behaviour of students the women lamented over was gambling. According to the women, university students have now introduced gambling into the town and this is a source of worry. There are a few of such game centres where gambling is done and that it is promoting laziness among the Waala youth. According to them, "our children hardly do any work in the house these days. They go out to gamble with the students. This is gradually destroying our homes. Our children are becoming thieves - they steal our monies for gambling purposes."

Conflicts also occur over threats of ejection and or even in extreme cases ejection of students from their rental apartments. In many such instances, students are ejected inappropriately without even the requisite compensation, such as refund of balances associated with rent payments. In general, ejections from one's accommodation are associated with alleged misbehaviour of students, described to include - disrespectful behaviour, uncooperative behaviour in payments of joint utility bills, lack of good care and or mishandling of rooms, and cleaning compounds, and cohabitation between male and female students. According to female FGD respondents contributing on the subject in Kambali:

Some students have no regard for their landlords/landladies. A year ago, one girl and her friend were ejected from their room because they were not participating in cleaning the compound house. Even sweeping their balcony (veranda) was a problem. Anytime the landlady asked the girl to sweep the back of their room during the dry season, the students murmured in Twi (southern Ghanaian language), show disrespectful behaviour and refuse to do so. Some students also make too much noise and don't like pay water and electricity bills although they use these utilities and bring their friends to come and cook and do everything they want in the house (FGD discussants (Waala women), Kambalie, July 15, 2013.).

As explained by female discussants, students can be ejected for unfair reasons and that such occurrences were common. They cite an example in which a male student was ejected 
without refund of outstanding rent balances in Kambali until the police intervened when the incident was reported. A discussant cited an example in which a female student was ejected the fourth time from her room for alleged indecent dressing by landladies/landlords. In the most recent incident, the female student was accordingly ejected from her room for indecent dressing. She cited that three quarters of her breasts are always showing and that she wears short dresses (mini-skirts) and trousers that expose her G-strings, beats and tattoos all the time. In yet another example, a pair of male students got ejected from their room in Kambali by the landlord because he did not like their behaviour and general life style - complaining they entertained many visitors including different girls in the house, noise making and arguments over football, and drinking of alcohol and drunkenness. In general, female discussants report that several ejections were unfair as in the following:

- Some land lords are very jealous and do not want anybody to visit us (student girls) especially in the night. We left our first apartment because the land lord who is in his early forties expressed interest in one of us but she did not agree to his proposal. He started preventing even our group mates from visiting us, fought with a number of male visiting students and so we eventually had to vacate his house for this house where we currently live.

- Some of the landlords too are just cheats, whenever light bills come, they don't show us the total sum but demand any amount of money from us for settlement of electricity bills. There are many instances in which students absorb utility bills of Waala families through the dishonest manoeuvring of landlords/land ladies where students share billing metres with them. They often argue that we use more electricity simply because we use rice boilers and electric irons - and yet they use irons and sometimes kettles for heating water. We have been quarrelling with them over unfair payment of utility bills.

- Some landlords or land ladies get provoked when female student tenants entertain different male visitors and this sometimes lead to conflicts and eviction.

- Some landlords also try to take undue advantage of their positions to make love proposals or 'befriend' us. When they do not succeed, they will surely find fault with you and eventually eject you from the house.

- Some too demand too many things very often from us. Things such as clothes, money, ingredients, and foodstuff among others. Sometimes, students meet these demands but when they don't, it leads to tensions in some cases.

Furthermore, landlords/landladies profile and apply higher rents to students and lower rates to non-students for the same type of residential accommodation. In extreme cases, landlords apply exorbitant rent targeted at ejection of particular students if such students put up social behaviour the host families dislike. According to male discussants from Dobile:

Conflicts between landlords and students over rent rates occur because some landlords want fast money and apply relatively higher rents on students who 
'miss behave'. They really charge some of the students very high rents. Although this is pathetic, the students call for such punitive measures, especially those that further rent rented rooms to their colleagues under hidden tenancy agreements without the consent of the landlords. When some landlords detect such cases, they apply higher rents to them than indigenes (Male discussants - students, Dobile, June, 2013).

It is very common for landlords to apply higher rents on students than indigenes or non-students. Students can pay pay double the prevailing rate. This is partly because of the high demand for accommodation by students in town because of the lack of adequate hostel accommodation on the university campus. In exceptional cases, higher rents are applied to students who are known to misconduct themselves. This happens very often in Dobile. (Male discussants - students, Dobile, June, 2013).

Female FGD discussants were divided as to whether landlords/landladies applied higher rents to students than the prevailing market price. While some agreed it happened others claimed it does not happen. For those who claim it happens, they explained that it happened to students who try cheating on landlords and landladies. They will rent a room at a very low price and bring on board other students as tenants under their own internal tenancy agreements. When house owners detect this, they increase the rent and ask the students to pay additional money or face eviction. In paying additional money, they end up paying very high rate per room. This is how it happens. In other instances, higher rates are simply targeted at students. But some landlords argue that it is meant to cover utility bills or maintain the housing - although it is not always the case. According to some discussants, some students do not take good care of their rooms. They use irons frequently, fridges and heaters and do not pay electricity bills. So we apply high rent rates to enable us settle these bills. It happens every academic year. For those who said no, they said students were not workers and as mothers themselves, they all have children in school, who will definitely stay in someone's house one day. And so, it was not fair to do that.

However, female student discussants unanimously reported that landlords or land ladies applied higher rents to students in general and that they often target unsuspecting newly admitted students who report and are in desperate need of accommodation. In some cases, continuing students are ejected from their rooms to make room for newly admitted unsuspecting students who are more willing to pay higher rents because they are new and desperately looking for accommodation to settle. They also explain that in extreme cases, landlord/ladies apply higher rent to continuing students as a way to ofejecting them from the house if they so wish. Discussants cite an example in which a female student was ejected from her room in a compound house in Kpaguri through the application of higher rent rate targeted at the student. While other students were asked to pay between GHC 300 and GHC 400 Ghana cedis, the particular student was asked to pay GHC 500 for similar accommodation and so the student packed and left the compound. 
Traders in the market, particularly, retailers in the market profile students and applying higher market prices above the prevailing market prices in the sale of vegetables and consumables, especially foodstuff. Male discussants in Dobile assert as follows:

We hear these stories all the time. That when you speak English in the market, the traders take you for a student and charge higher market prices for goods above the prevailing market prices. We understand it is market women who sell foodstuff and vegetable who do this most often but also those retailers in clothes (Male discussants - students, Dobile, June, 2013).

However, female discussants, particularly, traders themselves claim they don't quote higher markets prices for the students. According to them, it may be happening but none of them have done that to a student. They even claim to even reduce prices for students because as a discussant puts it - we all have children.

Nonetheless, female student discussants in Kambali and Bamahu corroborate the assertion that traders profiled students and applied higher market prices for goods above the prevailing market prices. They cite several instances and examples to buttress their stands:

- Here in Bamahu, it's happening, and it's even worst in Wa town. Once you cannot speak Waali (the local language) to bargain on the market price, they sell items s at a price higher than the prevailing market price to you. It's better with the super markets, but those selling vegetables on tables or in the market, and even food vendors, they do it very often.

- During one vacation, a market woman in the Bamahu daily market remarked to her colleague that "the students will leave and we will know the real market women and those cheats pretending to be market women". Accordingly, she said this to a fellow trader in Akan when she had a misunderstanding with her. The import of that statement was that her colleague trader cheated on students through unfair pricing (high) pricing and that she would not do well in business when the students are on vacation and actual prices prevail in the market.

- A discussant cited that she and her roommate wanted to buy a goat and the goat dealer put a price tag of GHC120.00. They refused to buy and instead gave money to their landlord, he bought that same goat for them at GH\$55.00.

- Even at the grinding mills, when we (students) go there to grind our small flour, tomatoes or pepper often little quantities, we pay more for services than the natives do.. In fact our mates who are natives are far better than us; they can challenge the prices of goods because they are knowledgeable about local pricing.

- A discussant narrates as follows: I went to the market with my friend to buy okro. There was already a woman before us who asked about the prices and the seller placed a price tag of GHC 5op. As we were speaking, the seller asked the buyer to give her GHC2.0O so that she will give her change to prevent us from knowing the price. She spoke in the local language Waali but the students had already understood her because they spoke Dagbani which is similar/close to Waali. Thinking that she had 
outsmarted the students, the trader told the students a unit of okro was selling at GHC 1.00. The students declined the price offer and boughtthesame quantity at GHC 5Op from another trader.

- Another discussant narrates, she and her roommate's experience: We have been buying from the market, but one day we sent a small boy to buy meat and green pepper in the market for us. We gave him GHC 2.00 for the meat and GHC 50p for the green pepper. When he brought the meat, it was much bigger in quantity than what we get when we go as students to buy at the same amount of money. For the same quantity of pepper the boy bought at GHC 50p, we would have bought it for double the price (GHC 1.00).

Finally, there is an increasing trend of love relationships between university students and indigenes in two main forms and these sometimes result in negative outcomes - social tensions in homes and teenage pregnancies. On the one hand, there is an increasing trend in teenage pregnancy partly, an outcome of social relationships between indigenous teenage girls and male university students. On the other hand, there is an increasing trend of female university students falling into love relationships with men (non-students) in town, including married men(what is termed the Alhaji phenomenon) leading to social tensions at home, hostile behaviour of wives towards female university students and occasionally, resulting in marriages that do not last. The following extracts from male FGD discussants in Bamahu shed light on the issues:

- Teenage pregnancy resulting from love relations between male university students and our children is common. We just had one recently in Bamahu where one student impregnated a JHS two girl. She has just delivered recently.

- In Dobile, a male university student impregnated a teenage Waala girl. She delivered a baby girl a week ago and she and the new born live in the next house, pointing his finger at the house.

- In a recent incident, amale student befriended one of our wives (an indigene's wife) and this led to domestic conflicts and eventual divorce.

- It's not common for us the men here to befriend female university students. This is because we can't have them because we are illiterates - and so we can't have them as our girlfriends.

- Here in Bamahu, conflicts between female university students and our wives occur; but it's not as result of us the men befriending the female students. Rather, it results from competition for water at the bore holes and standpipes. The student population have increased the population of the community to the point that water supply is inadequate for the population.

- Students indulge in open love and profane behaviour which indigenous families find distasteful and bad teachings to their children. 
- According to male discussants, here in Dobile, conflicts arise over husbands love relationships with university girls. We hear stories about 'UDS girls snatching husbands' in town and this often leads to domestic quarrels between spouses.

- It is rare for female university students to become pregnant out of relationships with indigenous Waala men. We have not heard about this except probably the big officers in town. It's rather common to hear of male university students impregnating their female counterparts. As for us, we can't get those girls easily because we lack formal education. How will one of us handle a female university student? A discussant asked, we are just not meant to get along with them in any courtship relationship.

\section{Discussion}

The interaction of students and indigenous Waala families has resulted in both positive and negative outcomes. There is 'compromised social acceptability' of students to live within indigenous Waala communities and families - but this is also driven by economic interest, rent payments indigenous house owners derive from the students.

The case of Waala communities and families letting in university students and living with them is the outcome of a compromise between the two to live together in order to achieve varying interest and goals consistent with integration in the sense of inclusionary orientation and goal for improving life opportunities, not of only the minority (UNRISD, 1994), but in this case the majority as well. The incidence of students and Waala living together cannot be described as social integration in the true sense of it because largely, indigenous Waala communities despise the social behaviour that students put up. From the perspective of the Waala, it is plausible to observe that social integration in terms of integrating university students has not occurred because the two groups tend to have much more culturally differentiated behaviours than common values that should bind them. Equally from the perspective of students, social integration cannot be said to occur in the true sense of it because students continue to live their social lives largely among themselves, exhibiting what can be described as the unique student way of life and culture, which indigenous Waala communities frown on. This has relevance for the assertion that among Hispanic and Native American college student, ethnicity influenced social integration process by students on campus (Murgui, et al., 1991).This is at variance with the position by Blau (1960) that social integration prevails if bonds of attraction unite its members. What seems to be happening is closer to organic solidarity, not in the context of the division of labour and associated interdependencies that Durkheim talks about; but more in the context of interdependence created by market forces, specifically demand and supply in the housing sector. Currently, students are a huge source of demand for rental accommodation and this has driven private investments in compound housing among indigenous Waala families as an important source of income for household sustenance. The average Waala family set aside a few rooms (1-2) rooms within their compounds for renting to students annually. This has become an important source of income for family sustenance so that although 
most families may despise much of the social behaviour of most students; they compromise and accommodate the students because of the economic benefits they gain from rent. In addition, students are a major source of market for tradable commodities and businesses in town. When they are on holidays, businesses are hit hard because they lose a significant market and when they return from holidays, they gain significant market. Thus, students seem to be spurring local economic growth and development and the indigenous people understand and appreciate this - thus, they accommodate students even if their behaviour is largely an affront to their culture and way of life.

According to the UNRISD (1994), social integration may also be understood as imposing some cultural values on a minority group for bringing about uniformity in society. In the case of interactions between students and Waala communities, it is the minority that has imposed a culture on the majority. The results suggest that although the Waala abhor the general behaviour of students; a process of acculturation has been imposed on the Waala community through the assimilation of these foreign cultural values of students by Waala youth much to the displeasure of their parents. Thus, a process of acculturation has been set in motion and driven by daily interactions between university students and Waala youth. In this case, the minority, the students are the ones who have imposed a 'student culture', foreign to Waala culture and traditions on the majority and host, the Waala. The analysis of these emerging dynamics in the relationships between students and landlords is consistent with the alternative understanding of social integration as a description of emerging patterns of human relations arising from minority and majority group interactions.

\section{Conclusion and Recommendations}

This paper examined the social integration of university students into Waala communities and families in Wa Municipality in Ghana. It concludes that social integration has been partial because both groups have much more differentiated ways of lives, culture and conflicts than the communalities that would otherwise bind them together in an emerging secular municipality. It further underscores that integration outcomes have been both positive and negative. For the positive outcomes, university students from varied ethnic backgrounds are socially accepted to live in shared compound houses by indigenous Waala families and this also enables modest cross-cultural learning's and exchanges. In addition, university students, especially female students have become role models of education to Waala youth, particularly, young girls - inspires them to attain higher education. In the negative domain, outcomes include conflict between students and Waala families over varied ways of life, conflicts over rents and ejection of students from rental apartments, differential application of rent rates and exploitation of students, exploitation of students through differential application of market prices (higher market prices) by petty traders on consumables in markets on students and finally, rising incidences of love relationships between students and indigenes leading to social tensions and undesirable social outcomes. 
The paper recommends that an integrated approach to District Development Planning (DDP) in the municipality within the context of decentralization. The approach should engender community and multi - stakeholder engagement involving the University for Development Studies and Wa Municipal Assembly (WMA) for the promotion of the following: education of students and communities on issues of social integration; creation of platforms for interactions and building bridges between communities and university students; strengthening the Rent Control Board ( $\mathrm{RCB}$ ) to discharge its function of regulating rent and resolving conflicts to avoid exploitation of students; and working effectively with the District Health Management Team to design and implement reproductive health services targeted at the indigenous youth and university students.

\section{References}

Blau, P. (1960). A theory of social integration. American Journal of Sociology. Vol. 65, No. 4, pp.545-556.

Hardy, C.L. (n.d). Theory of social integration. Retrieved August 7, 2013, from http://www.ehow. com/about_5399164_theory-social-integration.html

Ghana Statistical Service [GSS] (1984). Population and Housing Census of Ghana: Demographic and Economic Characteristics. Accra: Ghana Statistical Service.

Ghana Statistical Service [GSS] (2000). Population and Housing Census 2000. Accra: Ghana Statistical Service.

Ghana Statistical Service [GSS] (2008). Ghana Demographic and Health Survey 2008: Preliminary Report. Accra: Ghana Statistical Service.

Ghana Statistical Service [GSS] (2010). 2010 Population and Housing Census. Accra: Ghana Statistical Service.

Guralnick, M. J. (1999). The nature and meaning of social integration for young children with mild developmental delays in inclusive settings. Journal of Early Intervention, Vol. 22, No.1, pp.70-86.

Koramaz, K. E. (2013). The spatial context of social integration. Media Dordrecht:Springer Science-Business.

Krauße, R. (1991). Guanxi as a model of social integration. Retrieved March 3, 2016 from http:// www.humanities-online.deinfo@humanities-online.de

Marguia, E. et. al (1991). Ethnicity and the concept of social integration in Tinto's Model of Institutional Departure. Journal of College Students Development, Vl 32No. 5, pp. 433-39 (September 1991). 
Marijkkeanker (2011). Social integration -Emile Durkheim. StudyMode.com. Retrieved September 7,2013, from http://www.studymode.com/essays/Social-IntegrationEmile-Durkheim-795003.html

Münch, R. (1998). Globale dynamik, lokaleLebenswelt. Der schwierigeWeg in die Weltgesellschaft. Frankfurt: SuhrkampVerlag.

Songsore, J.(2003). The urban housing crisis in Ghana: Capital, the state versus the people. Ghana Social Science Journal. No. 2, No.1, pp. 1-31.

United Nations Research Institute for Social Development [UNRISD] (1994). Social integration: Approaches and issues. UNRISD Briefing Paper No. 1, World Summit for Social Development. 